\title{
Reservas Renováveis e Caracterização dos Aqüíferos Fissurais do Leste da Zona da Mata de Minas Gerais e Adjacências
}

\author{
José Augusto Costa Gonçalves (costa@degeo.ufop.br), Paulo Cyro Baptista Scudino, \\ Frederico Garcia Sobreira \\ Departamento de Geologia - UFOP \\ Campus Morro do Cruzeiro, CEP 35400-000, Ouro Preto, MG, BRA \\ Recebido em 11 de novembro de 2002; aceito em 30 de novembro de 2004
}

Palavras-chave: estações fluviométricas, águas superficiais e subterrâneas, hidrogramas, coeficiente de armazenamento.

\section{RESUMO}

O trabalho trata de uma caracterização hidrogeológica das bacias hidrográficas dos rios Pomba e Muriaé, tributários do rio Paraíba do Sul, considerando a correlação quantitativa existente entre as águas superficiais e as subterrâneas. Os hidrogramas analisados foram construídos com dados de descargas médias diárias em sete estações fluviométricas, sendo uma no rio Novo, quatro no rio Pomba e duas no rio Muriaé, localizadas respectivamente em: a. Usina Maurício; b. Guarani; c. Astolfo Dutra; d. Cataguases; e. Santo Antônio de Pádua; f. Patrocínio do Muriaé; g. Itaperuna. Para as bacias estudadas, os valores encontrados para a descarga subterrânea específica $\left(\mathrm{L} / \mathrm{s} / \mathrm{km}^{2}\right)$ e do coeficiente de recessão $(\alpha)$ respectivamente para as estações enumeradas foram: a. 12,3 / 0,00362; b. 13,7 / 0,00315; c. 12,8 / 0,00359; d. 12,6 / 0,00368; e. 10,9 / 0,00393; f. 9,9 / 0,00516; g. 10,8 / 0,00535.

Keywords: fluviometrical gauge station, superficial water and groundwater, hydrograms, storage coefficient.

\section{ABSTRACT}

The goal of this work is the hydrogeological characterization of the watersheds of the Pomba and Muriaé rivers, tributary of the Paraíba do Sul River, considering the existent quantitative correlation between the superficial and underground water. The studied hydrograms were based on data for daily average discharges at seven fluviometrical gauge stations: one in the Novo River, four in the Pomba River and two in the Muriaé River, located respectively at: a. Usina Maurício; b. Guarani; c. Astolfo Dutra; d. Cataguases; e. Santo Antônio de Padua; f. Patrocínio do Muriaé; g. Itaperuna. The specific underground discharge $(\mathrm{L} / \mathrm{s} / \mathrm{km} 2)$ and the recession coefficient $(\alpha)$ of these stations were respectively: a. 12,3 / 0,00362; b. 13,7/ 0,00315; c. $12,8 / 0,00359 ;$ d. $12,6 / 0,00368$; e. 10,9 / 0,00393; f. 9,9/0,00516; g. 10,8 / 0,00535. The results of the studied basins, for the specific underground discharge $(\mathrm{L} / \mathrm{s} / \mathrm{km} 2)$ and for the recession coefficient $(\alpha)$ for the enumerated stations were respectively: a. 12,3 / 0,00362; b. 13,7 / 0,00315; c. 12,8 / 0,00359; d. 12,6 / 0,00368; e. 10,9 / 0,00393; f. 9,9 / 0,00516; g. 10,8 / 0,00535. 


\section{INTRODUÇÃO}

Numa bacia hidrográfica, os cursos de água que mantêm regime natural de escoamento permanente, recebem águas subterrâneas restituídas quase que exclusivamente da descarga natural dos aqüíferos, oriunda da sua capacidade de armazenamento. Essas águas representam o escoamento de base ou a componente subterrânea do deflúvio superficial total no período de estiagem.

Na região de estudo, cujas bacias hidrográficas têm uma boa correlação de coincidência com suas respectivas bacias hidrogeológicas, em sua geometria e expressão territorial, em geral se cumpre a lei exponencial de esgotamento, a qual é aplicada na análise do hidrograma de deflúvio total (superficial e subterrâneo) ao longo do ano hidrológico. A separação e o cálculo do volume anual representam uma estimativa das reservas renováveis de água subterrânea na bacia, na qual freqüentemente se baseiam estratégias de gestão dos recursos hídricos.

O estudo da capacidade de armazenamento subterrâneo numa bacia hidrográfica é feito com base no deflúvio do período de esgotamento ou recessão hidrológica. O esgotamento significa um período sem recarga significativa dos aqǘf́eros e a conseqüente diminuição da descarga natural de restituição dos aqüíferos aos rios (condições de rio efluente), que se verifica ao longo do período de estiagem ou recessão, caracterizando o regime dos cursos de água em período de déficit pluviométrico. A descarga natural durante o período de recessão, via de regra é associada à restituição subterrânea, a qual está condicionada a um diferencial de carga hidráulica entre os aqüíferos e os canais luviais. A relação entre a carga hidráulica e a vazão do escoamento do fluxo de base é geralmente denominada de curva de esgotamento.

\section{ASPECTOS GERAIS DA ÁREA ESTUDADA}

A área de estudo abrange parte da Zona da Mata do Estado de Minas Gerais e uma pequena faixa territorial do noroeste do Estado do Rio de Janeiro, estando inserida nas bacias hidrográficas dos rios Pomba e Muriaé, contribuintes do rio Paraíba, e abrangendo uma superfície na ordem de $6.000 \mathrm{~km}^{2}$ (Figura 1).

O substrato da região é representado por rochas arqueanas a proterozóicas, constituindo o bloco crustal de Vitória (Haralyi e Hasui, 1982), cuja maior parte dos litossomas expostos é associada ao Cinturão de Alto Grau Atlântico (Leonardos e Fyfe, 1974). Suas unidades litológicas estão representadas no mapa da Figura 1. Segundo Oliveira (1983), a borda este-sudeste da área apresenta alta linearidade de traços estruturais, representada pelo padrão do Cinturão Móvel Costeiro. Segundo Brandalise (1976), Oliveira (1983) e Barbosa e Grossi Sad
(1983), as principais direções de falhamentos são paralelas à direção geral de foliação NNE-SSW, possuindo um estilo estrutural longitudinal e mergulhando para SE, denotando evidência de uma tectônica compressiva, podendo os mesmos terem sido reativados em variadas épocas.

Segundo Brandalise et al. (1993), três unidades geomorfológicas se destacam na porção centro ocidental. A unidade planaltos dissecados do centro-sul e leste de Minas se caracteriza pela dissecação fluvial sobre rochas précambrianas, que deu origem a um conjunto de colinas e cristas com altitudes entre $1.000 \mathrm{e} 1.200 \mathrm{~m}$ e vales encaixados cujas altitudes variam entre 750 e $800 \mathrm{~m}$. A unidade Serra da Mantiqueira caracteriza-se por escarpas muito dissecadas, onde se identificam níveis de 800 a $900 \mathrm{~m}$ de altitude. A unidade depressão do rio Paraíba do Sul teria se originado a partir do vale do rio Pomba e seus afluentes que atravessam perpendicularmente alinhamentos de cristas, acompanhando fraturas de direção NW-SE. A rede de drenagem encontra-se representada pelas bacias dos rios Pomba e Muriaé, cujas cabeceiras estão na Serra da Mantiqueira.

Nos extremos oeste, noroeste e norte da área, o clima é típico de regiões de altitudes elevadas, sendo caracterizado por verões brandos (temperatura média do mês mais quente inferior a $22^{\circ} \mathrm{C}$ ), índice pluviométrico entre $1.500 \mathrm{e}$ $1.700 \mathrm{~mm} /$ ano (maiores precipitações em dezembro e janeiro), estação mais seca entre maio e setembro (quando baixas temperaturas, média inferior a $16^{\circ} \mathrm{C}$ ). No resto da área, $\mathrm{o}$ clima é típico de regiões entre 700 e $400 \mathrm{~m}$ de altitude, apresentando verões quentes (média do mês quente superior a $22^{\circ} \mathrm{C}$ ), com temperaturas médias anuais superiores a $20^{\circ} \mathrm{C}$, médias do mês mais frio superiores a $16^{\circ} \mathrm{C}$, com pluviosidade geralmente inferior a $1.500 \mathrm{~mm}$ anuais.

\section{CARACTERIZAÇÃO HIDROGEOLÓGICA}

A região está inserida na Sub-Província Escudo Oriental 6-b do Mapa de Províncias Hidrogeológicas do Brasil, Pessoa et al. (1980). Ao se considerar o ambiente geológico da área de estudo, identificam-se duas categorias de aqǘferos: um meio granular, constituído por aqüíferos superficiais associados ao manto de alteração das rochas (saprólitos, elúvios e colúvios) e por depósitos aluvionares; e um meio fissural, representado por rochas cristalinas de diversas unidades litológicas.

A porção granular ocorre de modo generalizado constituindo-se numa importante fonte de recarga das rochas fraturadas subjacentes, atuando como um meio transmissor das águas pluviais infiltradas na superfície.

No aqüífero fissural, as características quantitativas e qualitativas das águas subterrâneas são condicionadas por fatores estruturais e litológicos, Costa (1986). A análise integrada destas informações sugere, em caráter preliminar, a 


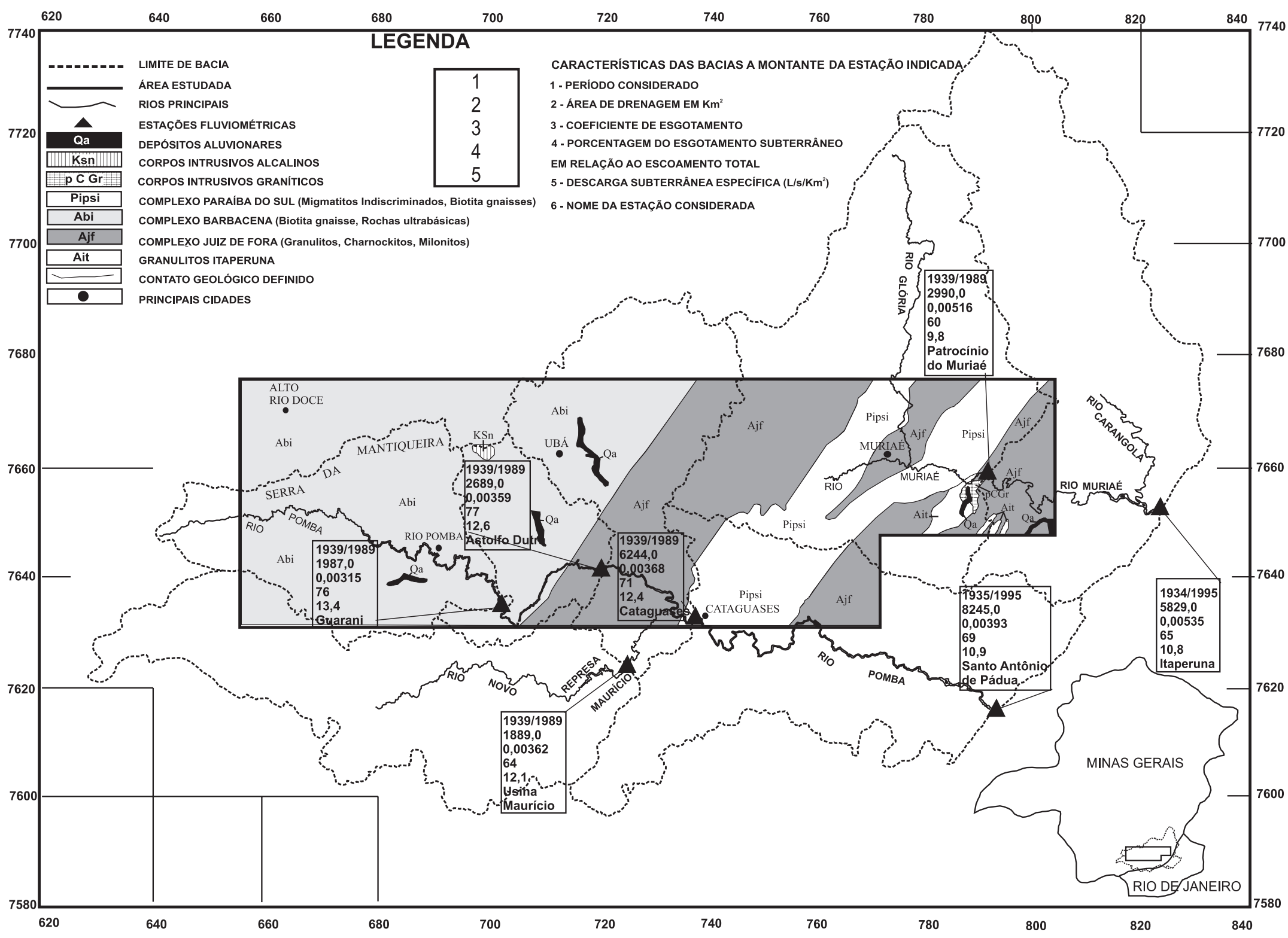

Figura 1. Mapa geológico e delimitação das sub-bacias da área estudada, Gonçalves (2001). 
compartimentação em dois domínios hidrogeológicos com características diferenciadas. Estes domínios são caracterizados por um ou mais tipos predominantes e bem definidos de rocha reservatório, estando associados às unidades geológicas regionais. As relações entre os aqüíferos e as unidades geológicas associadas, com os tipos de rochas dominantes, constam na Tabela 1.

Diante das dificuldades de um estudo hidrogeológico sistemático e convencional em rochas fissuradas da região nordeste de Minas Gerais, Peixoto et al. (1982) atentaram para a relação entre águas superficiais e subterrâneas a partir das análises de hidrogramas, na qual derivaram parâmetros que possibilitaram a quantificação das componentes superficiais e subterrâneas pelo método gráfico, a partir de hidrogramas representativos do escoamento total.

A análise dos parâmetros hidrológicos teve como metodologia os mesmos procedimentos de cálculo empregados por Peixoto et al. (1982), em regiões de rochas cristalinas com características hidrogeológicas similares à área em questão. Para o cálculo das componentes superficiais e subterrâneas do escoamento, utilizou-se o método de Barnes, Custódio e Llamas (1983). Foram utilizados dados fluviométricos de sete estações que monitoram as bacias hidrográficas dos rios Pomba e Muriaé, dentre as quais, quatro estações localizamse no rio Pomba, uma no rio Novo (tributário do rio Pomba) e duas no rio Muriaé. A delimitação das bacias estudadas e suas características estão representadas na Figura 1. Os dados das descargas médias diárias para as estações de Guarani, Astolfo Dutra, Usina Maurício, Cataguases e Patrocínio do Muriaé, utilizados na confeçãa dos hidrogramas, foram obtidos através da publicação "Deflúvios Superficiais no Estado de Minas Gerais", Copasa-MG/Hidrosistemas, Souza (1993). Para as descargas das estações de Itaperuna e Santo Antônio de Pádua, utilizaram-se dados obtidos junto a ANEEL.

\section{POTENCIAL E DISPONIBILIDADES HÍDRICAS}

As informações disponíveis de dados de testes de produção dos poços na região são insuficientes para mensurar as reais potencialidades dos aqüíferos, posto que fornecem somente a capacidade de extração de água através dos poços tubulares. Ademais, considerando-se o meio fissural, heterogêneo e anisotrópico, a análise e avaliação das reservas explotáveis, em seus diferentes domínios de ocorrência exige detalhamento das informações e de parâmetros hidrodinâmicos para a aquisição de valores médios que permitam estimativas mais próximas da realidade, visando a exploração sustentável da água subterrânea nesses aqüíferos fissurais.

A natureza dos aqüíferos estudados dificulta e reduz o estabelecimento de valores mais precisos dos parâmetros hidrodinâmicos, para a quantificação dos recursos hídricos armazenados. Para estimativas das reservas renováveis, são aqui apresentados os resultados obtidos a partir da análise de hidrogramas. Esses hidrogramas (Figuras 2, 3 e 4 ) mostram uma boa correlação entre o regime pluviométrico e o regime fluvial da região estudada.

O período de estiagem vai de abril (início do esgotamento) até fins de setembro - quando são registradas as menores taxas de vazão dos rios (fim do esgotamento). O período úmido, entre outubro e abril, coincide com as elevadas taxas pluviométricas e picos de cheias, quando se registram as maiores vazões.

A curva de esgotamento segue a referida lei exponencial, segundo a equação de Maillet, Castany (1967):

$$
\mathrm{Q}_{\mathrm{t}}=\mathrm{Q}_{0} \cdot \mathrm{e}^{-\alpha \cdot \Delta \mathrm{t}} \text { onde: }
$$

$\mathbf{Q}_{\mathrm{t}}=$ vazão no instante $\mathrm{t} \mathrm{em} \mathrm{m} / \mathrm{s}$;

$\mathbf{Q}_{0}=$ vazão no instante inicial do esgotamento $\mathrm{t}_{0}, \mathrm{em} \mathrm{m}^{3} / \mathrm{s}$;

$\boldsymbol{\alpha}=$ coeficiente de esgotamento, $\mathrm{em} \mathrm{dia}^{-1}$;

$\Delta \mathrm{t}=\mathrm{t}-\mathrm{t}_{0}$, o período desde o início do período de esgotamento, em dias;

t $=$ tempo, considerado no final do período de esgotamento, em dias;

$\mathbf{t}_{\mathbf{0}}=$ tempo, considerado no início do período de esgotamento, em dias;

e $=$ base dos logaritmos neperianos (2,71828).

Tomando-se os logaritmos decimais dos dois membros da equação, a expressão do coeficiente de esgotamento

Tabela 1. Aqüíferos da área de estudo.

\begin{tabular}{|c|c|c|}
\hline & Aqüíferos & Litologia predominante e unidades geológicas \\
\hline \multirow{2}{*}{ Meio granular } & Aluvial & Areias de depósitos aluviais - Quaternário \\
\hline & Coberturas detríticas e manto de alteração & Areias, siltes e argilas - Terciário-Quaternário \\
\hline \multirow[t]{2}{*}{ Meio fissural } & $\begin{array}{l}\text { Rochas da associação } \\
\text { xistos-gnaisses-migmatitos }\end{array}$ & $\begin{array}{l}\text { Biotita-xistos, biotita gnaisses, micaxistos, migmatitos indiscriminados } \\
\text { do Complexo Paraíba do Sul (Pipsi) e micaxistos, biotita gnaisses, } \\
\text { rochas ultrabásicas do Complexo Barbacena (Abi) }\end{array}$ \\
\hline & $\begin{array}{l}\text { Rochas da associação } \\
\text { charnockito-granulito-gnaisses-granitos }\end{array}$ & $\begin{array}{l}\text { charnockitos, granulitos, milonitos do Complexo Juiz de Fora (Ajf), } \\
\text { granulitos Itaperuna (Ait) e intrusões graníticas (pcGr) }\end{array}$ \\
\hline
\end{tabular}




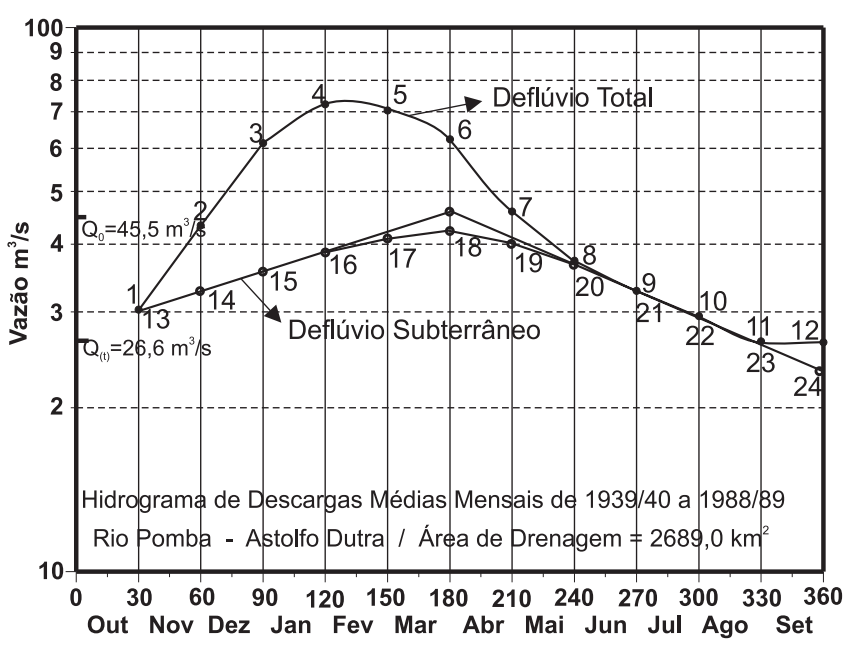

\begin{tabular}{|c|c|}
\hline $\begin{array}{c}\text { Deflúvio Total } \\
\left(\mathrm{m}^{3} \times 10^{6}\right)\end{array}$ & $\begin{array}{c}\text { Deflúvio Subterrâneo } \\
\left(\mathrm{m}^{3} \times 10^{6}\right)\end{array}$ \\
\hline $1-78,8$ & $13-78,8$ \\
\hline $2-112,2$ & $14-87,1$ \\
\hline $3-158,9$ & $15-93,3$ \\
\hline $4-187,4$ & $16-101,1$ \\
\hline $5-182,5$ & $17-106,3$ \\
\hline $6-161,7$ & $18-109,6$ \\
\hline $7-119,2$ & $19-103,9$ \\
\hline $8-96,7$ & $20-95,9$ \\
\hline $9-85,0$ & $21-85,0$ \\
\hline $10-76,5$ & $22-76,5$ \\
\hline $11-68,9$ & $23-68,7$ \\
\hline $12-68,4$ & $24-64,2$ \\
\hline
\end{tabular}

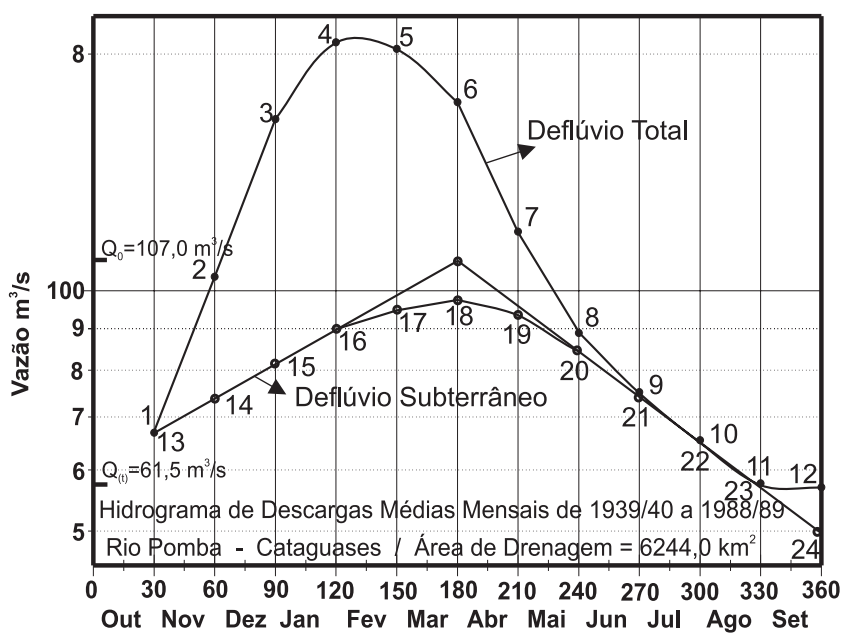

\begin{tabular}{|c|c|}
\hline $\begin{array}{c}\text { Deflúvio Total } \\
\left(\mathrm{m}^{3} \times 10^{6}\right)\end{array}$ & $\begin{array}{c}\text { Deflúvio Subterrâneo } \\
\left(\mathrm{m}^{3} \times 10^{6}\right)\end{array}$ \\
\hline $1-181,2$ & $13-181,2$ \\
\hline $2-268,5$ & $14-196,9$ \\
\hline $3-399,9$ & $15-215,1$ \\
\hline $4-485,5$ & $16-234,6$ \\
\hline $5-477,4$ & $17-245,4$ \\
\hline $6-417,6$ & $18-251,4$ \\
\hline $7-301,2$ & $19-241,0$ \\
\hline $8-233,3$ & $20-222,6$ \\
\hline $9-200,6$ & $21-199,6$ \\
\hline $10-178,1$ & $22-177,8$ \\
\hline $11-159,6$ & $23-159,6$ \\
\hline $12-158,1$ & $24-130,9$ \\
\hline
\end{tabular}

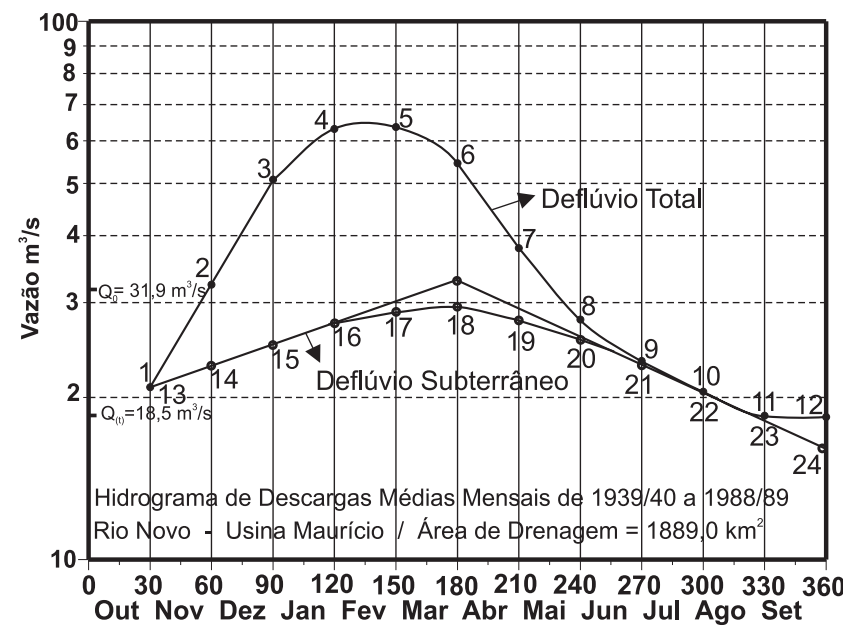

\begin{tabular}{|c|c|}
\hline $\begin{array}{c}\text { Deflúvio Total } \\
\left(\mathrm{m}^{3} \times 10^{6}\right)\end{array}$ & $\begin{array}{c}\text { Deflúvio Subterrâneo } \\
\left(\mathrm{m}^{3} \times 10^{6}\right)\end{array}$ \\
\hline $1-54,4$ & $13-54,4$ \\
\hline $2-84,2$ & $14-58,0$ \\
\hline $3-131,7$ & $15-62,5$ \\
\hline $4-163,6$ & $16-67,6$ \\
\hline $5-164,8$ & $17-70,5$ \\
\hline $6-141,5$ & $18-72,1$ \\
\hline $7-98,5$ & $19-68,7$ \\
\hline $8-72,6$ & $20-64,3$ \\
\hline $9-60,7$ & $21-58,6$ \\
\hline $10-53,4$ & $22-52,6$ \\
\hline $11-47,9$ & $23-47,2$ \\
\hline $12-47,7$ & $24-46,9$ \\
\hline
\end{tabular}

Figura 2. Hidrogramas dos rios Pomba e Novo, nas estações de Astolfo Dutra, Cataguases e Usina Maurício, respectivamente. 


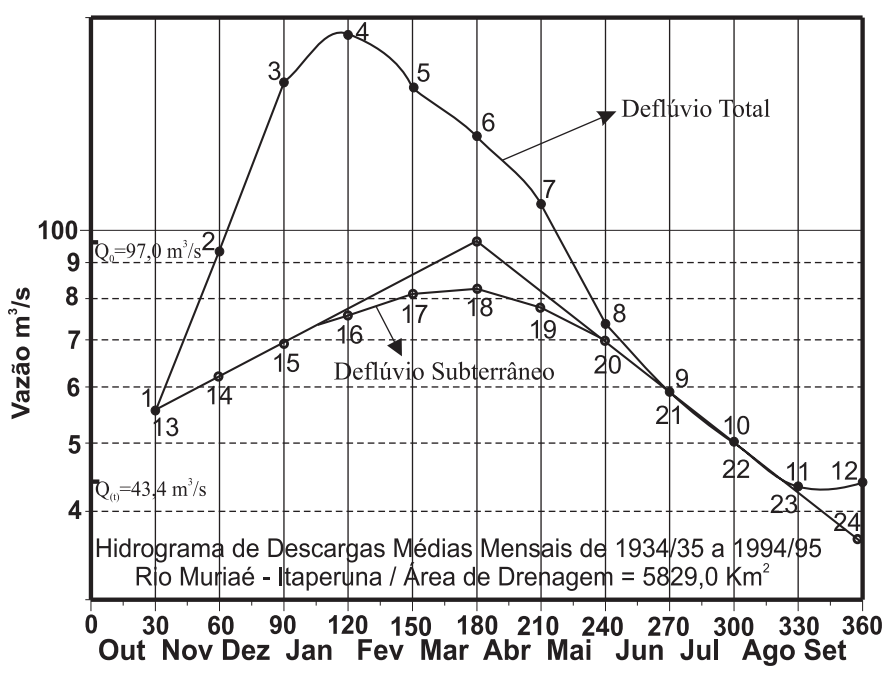

\begin{tabular}{|c|c|}
\hline $\begin{array}{c}\text { Deflúvio } \\
\text { Total/m }\end{array}$ & $\begin{array}{l}\text { Deflúvio } \\
\text { Subterrâneo/m }\end{array}$ \\
\hline $1-144,1152 \cdot 10^{6}$ & $13-144,1152 \cdot 10^{6}$ \\
\hline $2-241,8336 \cdot 10^{6}$ & $14-162 \cdot 10^{6}$ \\
\hline $3-419,904 \cdot 10^{6}$ & $15-181,44 \cdot 10^{6}$ \\
\hline $4-489,888 \cdot 10^{6}$ & $16-199,584 \cdot 10^{6}$ \\
\hline $5-396,576 \cdot 10^{6}$ & $17-208,656 \cdot 10^{6}$ \\
\hline $6-352,512 \cdot 10^{6}$ & $18-212,544 \cdot 10^{6}$ \\
\hline $7-282,528 \cdot 10^{6}$ & $19-199,548 \cdot 10^{6}$ \\
\hline $8-191,0304 \cdot 10^{6}$ & $20-176,256 \cdot 10^{6}$ \\
\hline $9-153,1872 \cdot 10^{6}$ & $21-153,1872 \cdot 10^{6}$ \\
\hline $10-130,1184 \cdot 10^{6}$ & $22-130,1184 \cdot 10^{6}$ \\
\hline $11-112,4928 \cdot 10^{6}$ & $23-111,456 \cdot 10^{6}$ \\
\hline $12-114,048 \cdot 10^{6}$ & $24-95,904 \cdot 10^{6}$ \\
\hline
\end{tabular}

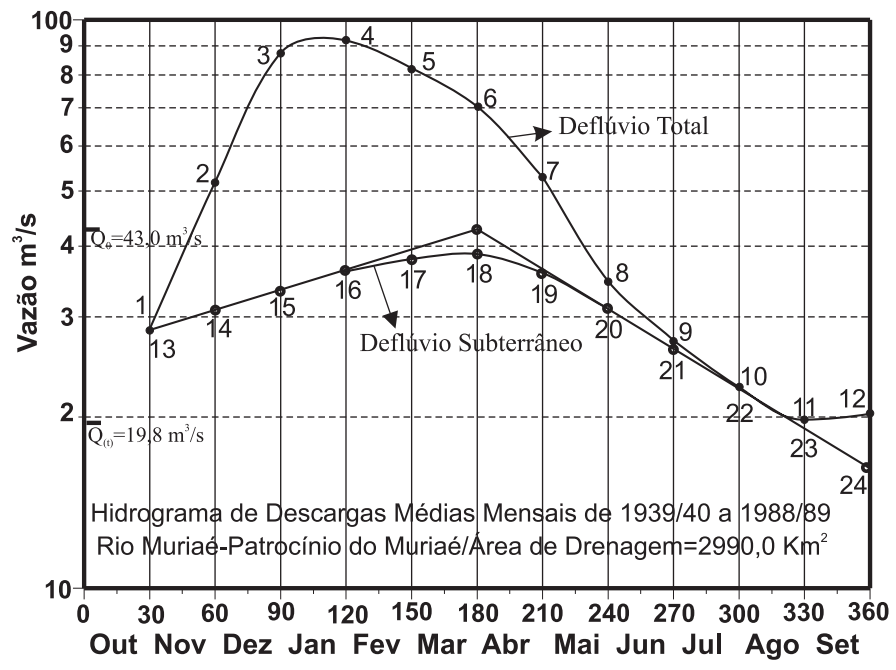

\begin{tabular}{|c|l|}
\hline $\begin{array}{c}\text { Deflúvio } \\
\text { Total } / \mathrm{m}^{3}\end{array}$ & $\begin{array}{l}\text { Deflúvio } \\
\text { Subterrâneo/m }\end{array}$ \\
\hline $1-73,872 \cdot 10^{6}$ & $13-73,872 \cdot 10^{6}$ \\
\hline $2-134,0064 \cdot 10^{6}$ & $14-78,7968 \cdot 10^{6}$ \\
\hline $3-226,2816 \cdot 10^{6}$ & $15-86,3136 \cdot 10^{6}$ \\
\hline $4-238,7232 \cdot 10^{6}$ & $16-93,5712 \cdot 10^{6}$ \\
\hline $5-212,2848 \cdot 10^{6}$ & $17-95,904 \cdot 10^{6}$ \\
\hline $6-186,624 \cdot 10^{6}$ & $18-98,496 \cdot 10^{6}$ \\
\hline $7-137,1168 \cdot 10^{6}$ & $19-92,016 \cdot 10^{6}$ \\
\hline $8-89,9424 \cdot 10^{6}$ & $20-81,9072 \cdot 10^{6}$ \\
\hline $9-70,5024 \cdot 10^{6}$ & $21-70,5024 \cdot 10^{6}$ \\
\hline $10-60,6528 \cdot 10^{6}$ & $22-60,6524 \cdot 10^{6}$ \\
\hline $11-51,5808 \cdot 10^{6}$ & $23-51,5808 \cdot 10^{6}$ \\
\hline $12-52,6176 \cdot 10^{6}$ & $24-43,8048 \cdot 10^{6}$ \\
\hline
\end{tabular}

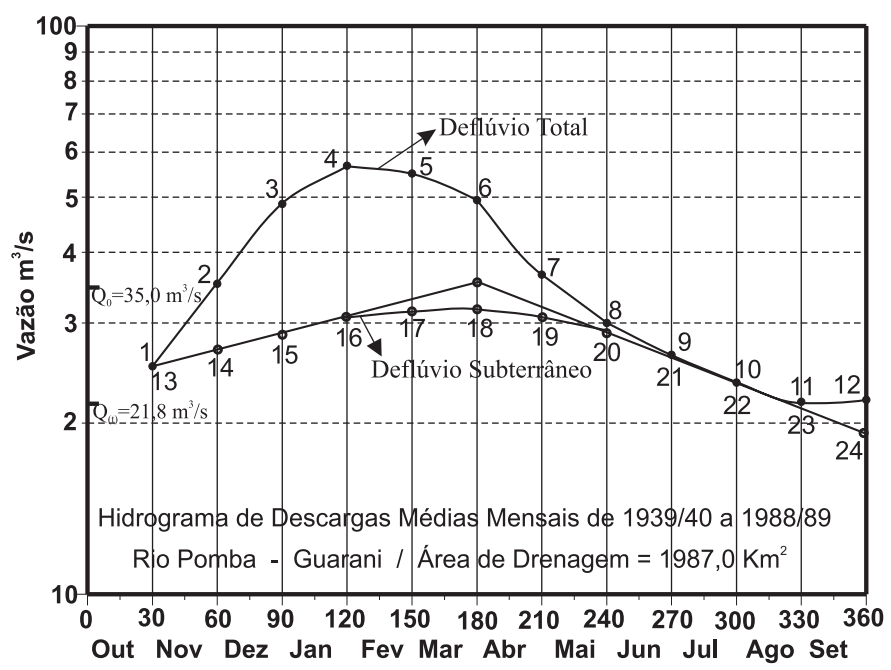

\begin{tabular}{|c|c|}
\hline $\begin{array}{c}\text { Deflúvio } \\
\text { Total/m }\end{array}$ & $\begin{array}{l}\text { Deflúvio } \\
\text { Subterrâneo/m }\end{array}$ \\
\hline $1-65,3184 \cdot 10^{6}$ & $13-65,3184 \cdot 10^{6}$ \\
\hline $2-91,2384 \cdot 10^{6}$ & $14-69,7248 \cdot 10^{6}$ \\
\hline $3-126,2304 \cdot 10^{6}$ & $15-74,6496 \cdot 10^{6}$ \\
\hline $4-147,4848 \cdot 10^{6}$ & $16-79,5744 \cdot 10^{6}$ \\
\hline $5-142,560 \cdot 10^{6}$ & $17-80,352 \cdot 10^{6}$ \\
\hline $6-128,0448 \cdot 10^{6}$ & $18-82,4256 \cdot 10^{6}$ \\
\hline $7-94,608 \cdot 10^{6}$ & $19-80,6112 \cdot 10^{6}$ \\
\hline $8-77,76 \cdot 10^{6}$ & $20-74,6496 \cdot 10^{6}$ \\
\hline $9-68,4288 \cdot 10^{6}$ & $21-68,4288 \cdot 10^{6}$ \\
\hline $10-62,7264 \cdot 10^{6}$ & $22-62,208 \cdot 10^{6}$ \\
\hline $11-56,5056 \cdot 10^{6}$ & $23-56,5056 \cdot 10^{6}$ \\
\hline $12-57,024 \cdot 10^{6}$ & $24-51,84 \cdot 10^{6}$ \\
\hline
\end{tabular}

Figura 3. Hidrogramas dos rios Muriaé e Pomba, nas estações de Itaperuna, Patrocínio do Muriaé e Guarani, respectivamente. 


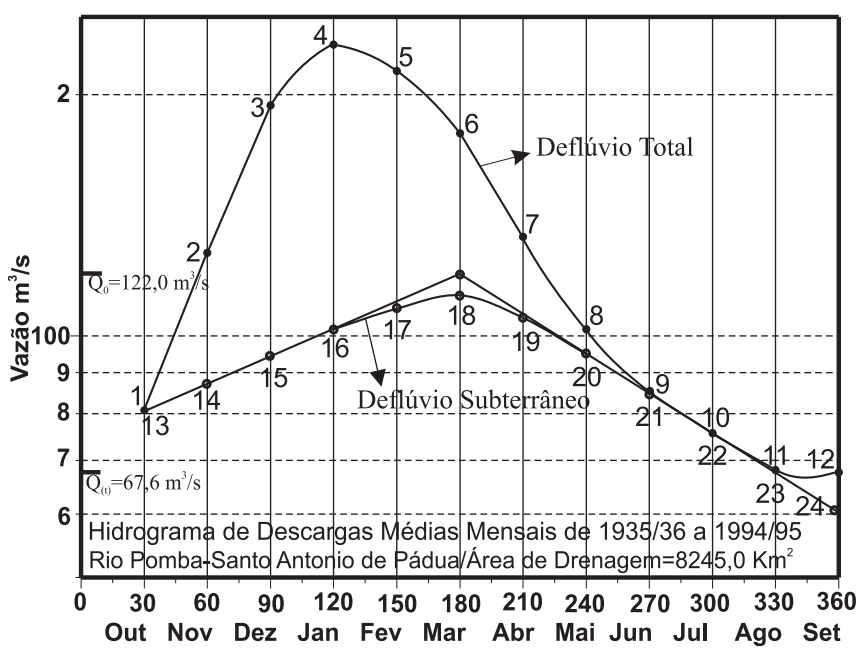

\begin{tabular}{|c|l|}
\hline $\begin{array}{c}\text { Deflúvio } \\
\text { Total } / \mathrm{m}^{3}\end{array}$ & $\begin{array}{l}\text { Deflúvio } \\
\text { Subterrâneo/m }\end{array}$ \\
\hline $1-209,4336 \cdot 10^{6}$ & $13-209,4336 \cdot 10^{6}$ \\
\hline $2-329,184 \cdot 10^{6}$ & $14-228,096 \cdot 10^{6}$ \\
\hline $3-502,848 \cdot 10^{6}$ & $15-247,536 \cdot 10^{6}$ \\
\hline $4-598,752 \cdot 10^{6}$ & $16-269,568 \cdot 10^{6}$ \\
\hline $5-554,688 \cdot 10^{6}$ & $17-283,824 \cdot 10^{6}$ \\
\hline $6-463,968 \cdot 10^{6}$ & $18-292,896 \cdot 10^{6}$ \\
\hline $7-344,736 \cdot 10^{6}$ & $19-274,752 \cdot 10^{6}$ \\
\hline $8-264,384 \cdot 10^{6}$ & $20-250,128 \cdot 10^{6}$ \\
\hline $9-224,208 \cdot 10^{6}$ & $21-224,208 \cdot 10^{6}$ \\
\hline $10-200,1024 \cdot 10^{6}$ & $22-200,1024 \cdot 10^{6}$ \\
\hline $11-176,5152 \cdot 10^{6}$ & $23-176,5152 \cdot 10^{6}$ \\
\hline $12-175,2192 \cdot 10^{6}$ & $24-158,112 \cdot 10^{6}$ \\
\hline
\end{tabular}

Figura 4. Hidrograma do rio Pomba na estação de Santo Antônio de Pádua.

$(\alpha)$ resulta em:

$$
\alpha=\left(\log \mathrm{Q}_{0}-\log \mathrm{Q}_{\mathrm{t}}\right) / 0,4343 \Delta \mathrm{t}
$$

Através dessa expressão e dos hidrogramas contendo dados diários de descarga, obteve-se os valores dos coeficientes de esgotamento de alguns trechos das sub-bacias dos rios Pomba, Novo e Muriaé, referentes às estações fluviométricas analisadas, conforme mostrado na Tabela 2.

O coeficiente de esgotamento " $\alpha$ ", caracteriza a descarga dos aqüíferos em regime não influenciado (ausência de precipitação), é inversamente proporcional à extensão (dimensão linear) dos reservatórios subterrâneos e diretamente proporcional à porosidade efetiva e a condutividade hidráulica dos aqüíferos, caracterizando o comportamento dos sistemas aqǘferos de uma bacia hidrográfica. Assim, quanto maiores forem os parâmetros hidrodinâmicos e dimensionais dos aqüíferos, tanto menores serão os valores do coeficiente de esgotamento e mais elevada a capacidade de armazenamento subterrâneo. A determinação do coeficiente de esgotamento é feita através de soluções gráficas das curvas de esgotamento, utilizando-se principalmente as fórmulas de Maillet e Tison, Castany (1967).

Dentro dos sistemas aqüíferos, considera-se que o equilíbrio de fluxo das águas que entram seja igual aos volumes de saída. Assim, ao se conhecer o quanto é restituído das águas subterrâneas aos rios, pode-se estimar a contribui- ção das águas subterrâneas para o deflúvio total, e ainda determinar o deflúvio subterrâneo. Esses parâmetros são equivalentes à capacidade de armazenamento subterrâneo das bacias e correspondem às reservas reguladoras, que segundo Castany (1967) é "o volume de água livre armazenado em uma seção dos aqüíferos limitada por dois níveis piezométricos extremos, mínimo e máximo da superfície piezométrica, ao longo de um período considerado".

A determinação da capacidade de armazenamento é dada pela expressão:

$$
\mathrm{V}=\mathrm{Q}_{0} / \alpha
$$

Como $\alpha$, na curva de esgotamento, se calcula em [L/dias], e Q é expresso em m³/s, tem-se:

$$
\mathrm{V}\left(\mathrm{m}^{3}\right)=86400 \mathrm{Q}_{0} / \alpha
$$

expressão que representa o volume global de água subterrânea armazenado no instante $t_{0}$, acima do nível de base, pelos sistemas aqüíferos que ocorrem na sub-bacia considerada.

Os resultados obtidos são apresentados nas Tabelas $2 \mathrm{e}$ 3. Além de dados físicos das sub-bacias, como área de drenagem e distribuição percentual dos aqüíferos, os quadros mostram dados referentes aos deflúvios total, superficial, subterrâneo, capacidade de armazenamento, descarga subterrânea específica e coeficiente de esgotamento. 
Tabela 2. Coeficiente de esgotamento das sub-bacias dos rios Pomba, Muriaé e Novo.

\begin{tabular}{|c|c|c|c|c|c|c|c|c|c|c|c|}
\hline \multicolumn{12}{|c|}{ Distribuição percentual dos aqüíferos nas respectivas sub-bacias } \\
\hline \multirow{2}{*}{$\begin{array}{c}\text { Sub-bacias } \\
\text { Rios }\end{array}$} & \multirow{2}{*}{$\begin{array}{l}\text { Local das estações } \\
\text { fluviométricas }\end{array}$} & \multirow{2}{*}{$\begin{array}{c}\text { Área de } \\
\text { drenagem } \\
\left(\mathrm{km}^{2}\right)\end{array}$} & \multicolumn{7}{|c|}{ Distribuição dos Aqüíferos (\%) } & \multirow{2}{*}{$\begin{array}{l}\text { Coeficiente de } \\
\text { esgotamento } \\
\left(\mathrm{dia}^{-1}\right)\end{array}$} & \multirow{2}{*}{$\begin{array}{c}\text { Descarga subterrânea } \\
\text { específica } \\
\left(\mathrm{L} / \mathrm{s} / \mathrm{km}^{2}\right)\end{array}$} \\
\hline & & & PcGr & KSn & Ait & Ajf & Abi & Pipsi & Qa & & \\
\hline Pomba & Guarani & 1.987 & - & - & - & - & 99,10 & - & 0,90 & 0,00315 & 13,7 \\
\hline Pomba & Astolfo Dutra & 2.689 & - & 0,13 & - & 4,70 & 94,30 & - & 0,87 & 0,00359 & 12,8 \\
\hline Novo & Usina Maurício & 1.889 & - & - & - & 49,50 & 48,20 & 2,30 & - & 0,00362 & 12,3 \\
\hline Pomba & Cataguases & 6.244 & - & 0,06 & - & 27,00 & 71,40 & 0,70 & 0,84 & 0,00368 & 12,6 \\
\hline Pomba & Santo Antônio de Pádua & 8.245 & 0,29 & 0,02 & 0,84 & 31,30 & 54,20 & 12,50 & 0,85 & 0,00393 & 10,9 \\
\hline Muriaé & Patrocínio do Muriaé & 2.990 & 0,80 & - & 2,60 & 47,30 & - & 48,90 & 0,40 & 0,00516 & 9,9 \\
\hline Muriaé & Itaperuna & 5.829 & 1,90 & - & 5,00 & 46,70 & - & 43,50 & 2,90 & 0,00535 & 10,8 \\
\hline
\end{tabular}

Tabela 3. Características hidrogeológicas das sub-bacias dos rios Pomba, Muriaé e Novo.

\begin{tabular}{|c|c|c|c|c|c|c|c|}
\hline $\begin{array}{c}\text { Sub-bacias } \\
\text { Rios }\end{array}$ & $\begin{array}{l}\text { Local das estações } \\
\text { fluviométricas }\end{array}$ & Período & $\begin{array}{c}\text { Area de } \\
\text { drenagem } \\
\left(\mathrm{km}^{2}\right)\end{array}$ & $\begin{array}{c}\text { Deflúvio } \\
\text { total } \\
\left(\mathrm{m}^{3} \times 10^{6} / \mathrm{ano}\right)\end{array}$ & $\begin{array}{c}\text { Deflúvio } \\
\text { superficial } \\
\left(\mathrm{m}^{3} \times 10^{6} / \mathrm{ano}\right)\end{array}$ & $\begin{array}{c}\text { Deflúvio } \\
\text { subterrâneo } \\
\left(\mathrm{m}^{3} \times 10^{6} / \mathrm{ano}\right)\end{array}$ & $\begin{array}{c}\text { Capacidade de } \\
\text { armazenamento } \\
\left(\mathrm{m}^{3} \times 10^{6} / \mathrm{ano}\right)\end{array}$ \\
\hline Pomba & Guarani & $1939 / 40-1988 / 89$ & 1.987 & $1.117,9$ & 271,7 & 846,2 & 960,0 \\
\hline Pomba & Astolfo Dutra & $1939 / 40-1988 / 89$ & 2.689 & $1.396,2$ & 322,9 & $1.070,4$ & $1.095,0$ \\
\hline Novo & Usina Maurício & $1939 / 40-1988 / 89$ & 1.889 & $1.121,0$ & 397,6 & 723,4 & $7.613,7$ \\
\hline Pomba & Cataguases & $1939 / 40-1988 / 89$ & 6.244 & $3.461,0$ & $1.004,9$ & $2.456,1$ & $2.512,1$ \\
\hline Pomba & Santo Antônio de Pádua & $1935 / 36-1994 / 95$ & 8.245 & $4.044,0$ & $1.228,8$ & $2.815,1$ & $2.682,1$ \\
\hline Muriaé & Patrocínio do Muriaé & $1939 / 40-1988 / 89$ & 2.990 & $1.534,2$ & 606,8 & 927,4 & 720,0 \\
\hline Muriaé & Itaperuna & $1934 / 35-1994 / 95$ & 5.829 & $3.028,2$ & $1.053,3$ & $1.974,8$ & $1.566,5$ \\
\hline
\end{tabular}

\section{CONSIDERAÇÕES FINAIS}

O conhecimento da capacidade reguladora dos aqüíferos sobre a descarga natural dos rios, mesmo que em escala regional, oferece subsídios que auxiliam na estimativa das reservas explotáveis, visando melhor conduzir o processo de gestão dos aqüíferos. Para quantificar estas reservas, métodos diretos que permitem estimar as restituições subterrâneas dos aqüíferos para os rios, a partir de dados observados (medidos) de longo período, fornecem informações confiáveis.

A estimativa das reservas renováveis possibilita o dimensionamento da capacidade de explotação dos aqüíferos, buscando-se preservar o equilíbrio hídrico do sistema, ou seja, a manutenção do fluxo natural dos rios. A legislação do Estado de Minas Gerais, seguida pelo IGAM - Instituto Mineiro de Gestão das Águas, órgão responsável pela gestão dos recursos hídricos desse estado, considera sustentável um nível de explotação que resulte, para cada subbacia, a manutenção de vazão dos mananciais em 70\% da $\mathrm{Q}_{7,10}$, isto é, uma vazão correspondente a $70 \%$ da vazão mínima minimorum observada durante sete dias consecutivos, em dez anos de recorrência.

Para o somatório de todas as sub-bacias (Tabela 3), abrangendo uma área de cerca de $14.000 \mathrm{~km}^{2}$, as reservas reno- váveis foram avaliadas na ordem de $17.149,4 \times 10^{6} \mathrm{~m}^{3} /$ ano. Já especificamente para a área foco desse estudo (Figura 1), de aproximadamente $6.000 \mathrm{~km}^{2}$, estima-se um valor de $2.471,8 \times 10^{6} \mathrm{~m}^{3} /$ ano. De acordo com Rebouças et al. (1994), $25 \%$ do volume estimado para as reservas renováveis, representariam a disponibilidade explotável dos aqüíferos que no referido caso da área estudada corresponde a $617,95 \times 10^{6} \mathrm{~m}^{3} /$ ano.

O percentual do deflúvio subterrâneo com relação ao deflúvio total, dentro de uma sub-bacia, apresenta valores bastante elevados, superiores a $60 \%$ para todas as estações, independente do período.

A descarga subterrânea específica reflete a capacidade de restituição subterrânea dos aqüíferos por $\mathrm{km}^{2}$, caracterizando a potencialidade dos aqüíferos que ocorrem na bacia. Dentro desse propósito, observa-se que, nas sub-bacias drenadas para o rio Pomba, as contribuições decrescem de montante para jusante, enquanto para as sub-bacias do rio Muriaé ocorre o inverso.

A estação do rio Novo, em Usina Maurício, entre todas, apresenta a menor área de drenagem e a maior capacidade de armazenamento.

Os coeficientes de esgotamento variam de 0,00315 a 0,00362 para as estações fluviométricas que drenam para o rio Pomba, indicando grande capacidade de infiltração e 
armazenamento que, entretanto, não condizem com bacias onde predominam aqüíferos fissurados. A presença de aqüíferos granulares de cobertura pode explicar essa condição. Já os coeficientes de esgotamento das estações situadas na sub-bacia do rio Muriaé apresentam valores um pouco maiores $(0,00516$ e 0,00535$)$, portanto mais compatíveis com as características hidrogeológicas de bacias representadas por aqüíferos fissurados.

\section{REFERÊNCIAS BIBLIOGRÁFICAS}

BARBOSA, A. L. M.; GROSSI SAD, J. H. Reinterpretação das "Séries" Juiz de Fora e Paraíba do Sul em Minas Gerais e Rio de Janeiro. In: SIMPÓSIO DE GEOLOGIA DE MINAS GERAIS, 2., 1983, Belo Horizonte. Anais... Belo Horizonte: SBG-MG, 1983.p. 01-18.

BRANDALISE, L. A.; PINTO, C. P.; VIANA, H. S.; BRUNO, E. M.; ZUCCHETTI, M. Província Alcalina da Mantiqueira, Serra da Mantiqueira-MG. Revista da Escola de Minas, Ouro Preto, v. 45, n. 1/2, p. 179-180, 1992.

BRANDAliSE, L. A. Projeto Vale do Paraíba. Relatório Final. Belo Horizonte: DNPM/CPRM, 1976. 441 p.

CASTANY, G. Traité pratique des eaux souterraines. 2. ed. Paris: Dunod, 1967.661 p.

COSTA, W. D. Análise dos fatores que atuam no aqüifero fissural: área piloto dos Estados da Paraíba e Rio Grande do Norte. 1986. 225 p. Tese (Doutorado) - Instituto de Geociências, Universidade de São Paulo, São Paulo.

CUSTÓDIO, E.; LLAMAS, M. R. Hidrologia subterrânea. 2ed. Barcelona: Omega, 1983. 2 v.

GONÇALVES, J. A. C. Contribuição à hidrogeologia e à hidroquímica do leste da Zona da Mata de Minas Gerais e extremo noroeste do Estado do Rio de Janeiro. 2001. 102p. Dissertação (Mestrado) - Departamento de Geologia, Universidade Federal de Ouro Preto, Ouro Preto.

HARALYI, N. L. E.; HASUI, Y. Compartimentação geotectônica do Brasil Oriental com base na informação geofísica. In: CONGRESSO BRASILEIRO DE GEOLOGIA, 32., 1982, Salvador. Anais... Salvador: SBG, 1982. v. 1, p. $374-385$.

LEONARDOS JR., O. H.; FYFE, W. S. Ultrametamorphism and melting of a continental margin in the Rio de Janeiro region. Contributions to Mineralogy and Petrology, v. 45, p. 201-214, 1974.
OLIVEIRA, M. A. F. As rochas granulíticas da Faixa Paraíba do Sul. Revista Brasileira de Geociências, v. 13, n. 2, p. 84-92, 1983.

PEIXOTO, C. A. M.; JARDIM, F. G.; COSTA, P. C. G. Potencial hidrogeológico da Região Nordeste de Minas Gerais. In: CONGRESSO BRASILEIRO DE ÁGUAS SUBTERRÂNEAS, 2., 1982, Salvador. Anais... Salvador: ABAS, 1982. p. $89-110$.

PESSOA, M. D.; MENTE, A.; LEAL, O. Províncias hidrogeológicas do Brasil. In: CONGRESSO BRASILEIRO DE ÁGUAS SUBTERRÂNEAS, 1., 1980, Recife. Anais... Recife:ABAS, 1980.p. 461-474.

REBOUÇAS, A. C.; RICCOMINI, C.; ELLERT, N.; DUARTE, U.; MELITO, K. M.; SENF, L. A.; SOUZA, J. C. S. Diagnóstico hidrogeológico da Região Metropolitana de São Paulo, uso e proteção. In: CONGRESSO BRASILEIRO DE ÁGUAS SUBTERRÂNEAS, 8., 1994, Recife. Anais... Recife: ABAS: DNPM: CPRM, 1994.p. 93-102.

SOUZA, S. M. T. Deflúvios superficiais do estado de Minas Gerais. Belo Horizonte: Hidrosistemas-Engenharia de Recursos Hídricos Ltda.: Copasa-Companhia de Saneamento de Minas Gerais, 1993. 264 p. 